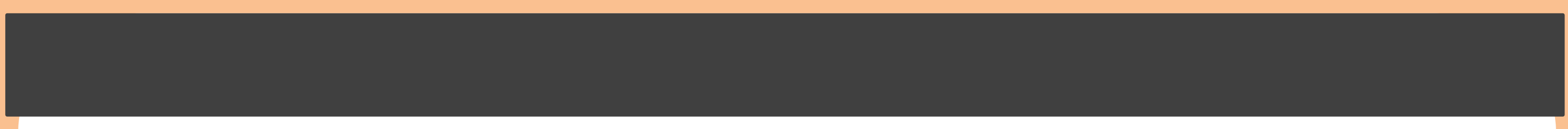

\title{
Use of the LEE INDEX for the prediction of CARDIOVASCULAR MORBIDITY and MORTALITY after HIP FRACTURE SURGERY.
}

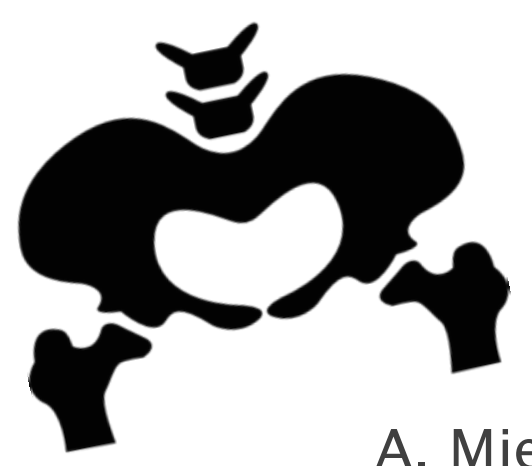

P. Martín Serrano, D. Gutiérrez Martínez,

A. Mjertan, A. Santa Cruz Hernando, N. Olmos Molpeceres, J. Torrente Pérez

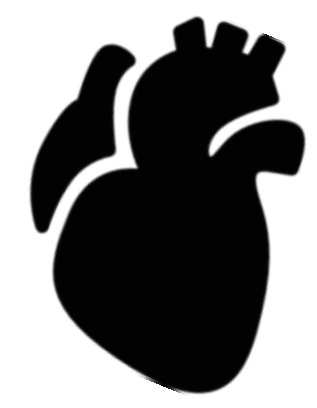

Hospital Universitario de La Princesa - Madrid (Spain)

\section{CONGLUSIONS}

The Lee index allows a moderately good discrimination of patients at low risk of patients at high risk of cardiac

The Lee Index helps us identify patients at greater risk and improve their study and optimization as far as possible to face surgery, as well as pointing out those who would benefit from modifications in the postoperative follow-up.

It should be added to our daily clinical practice.
Hip fracture is one of the main health problems of the elderly population. The appearance of medical complications during hospital admission is very high. Overall hospital mortality is $5 \%$, ranging from $2 \%$ to $8 \%$. Reaching $30 \%$ of patients 12 months after fracture.

On the other hand, the Lee index is considered the best index available for prediction of cardiac risk in non-cardiac surgery. In this study we have tried to relate its value to cardiovascular morbidity and mortality derived from hip fracture surgery.

\section{THHODUCHON}

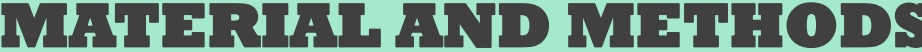

An observational study was carried out analyzing all the hip fracture surgeries performed in our hospital over a month. 32 consecutive patients were selected.
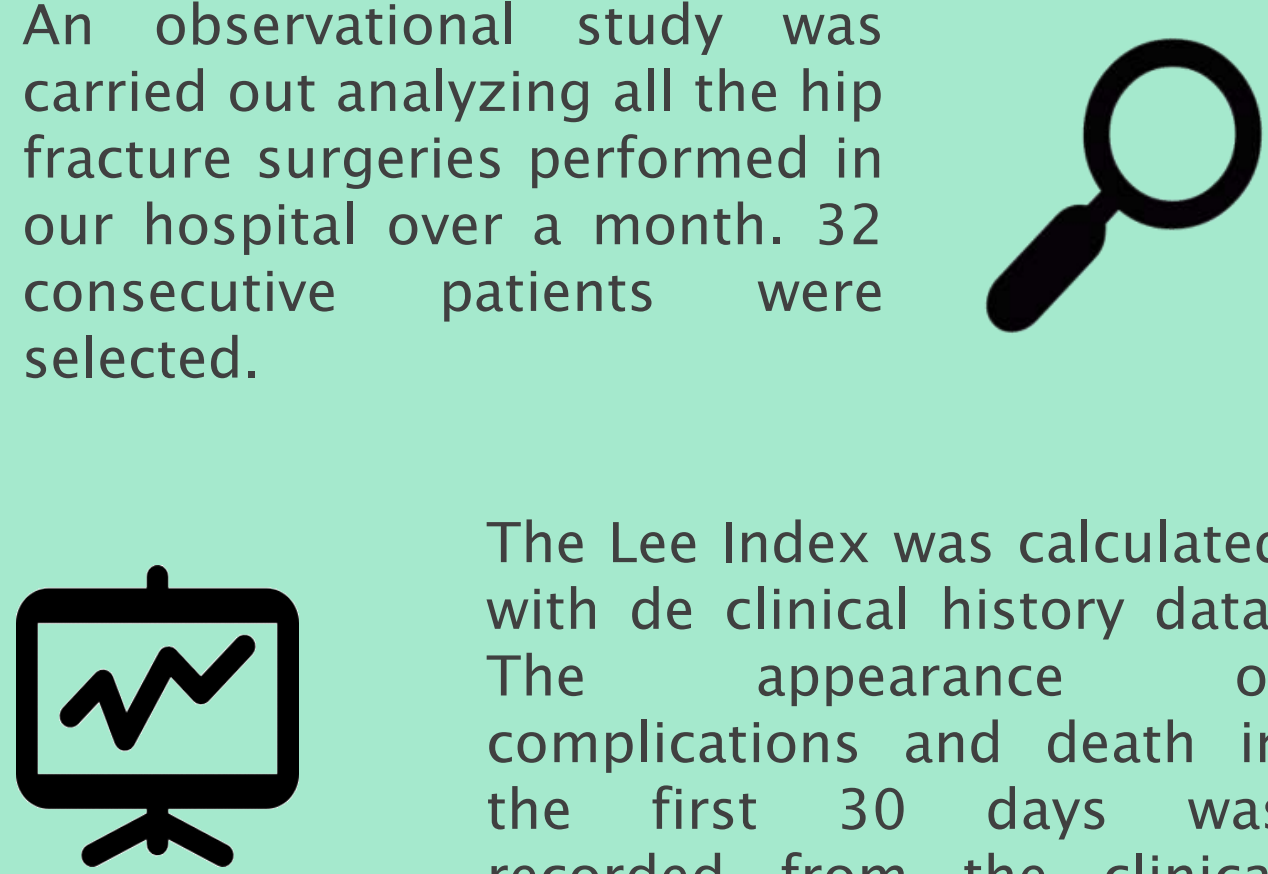

The Lee Index was calculated with de clinical history data. The appearance of complications and death in the first 30 days was recorded from the clinical evolution.

Data analysis was performed with the IBM SPSS Statistics. We carry out a comparison of the means through the Mann-Whitney $U$ test. The comparison of proportions

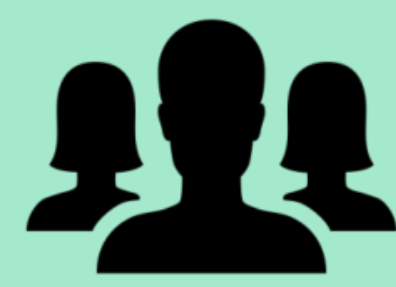
was made by the Fisher's exact test

\section{RESULts}

We analyzed a total of 32 patients (78.1\% of women)

\section{DOWNLOAD HERE} THE ABSTRACT

\section{$71.9 \%$ of patients had a Lee Index of 0} $15.6 \%$ of 1 and $12.5 \% \geq 2$

An increase in the value of the Lee Index is statistically related in our sample with a higher incidence of CRP and death $(p=0.006)$.

According to Fisher's exact test, a Lee Index $\geq 2$ was statistically related to the probability of mortality $(p=0.013)$. $50 \%$ of patients with these scores died.

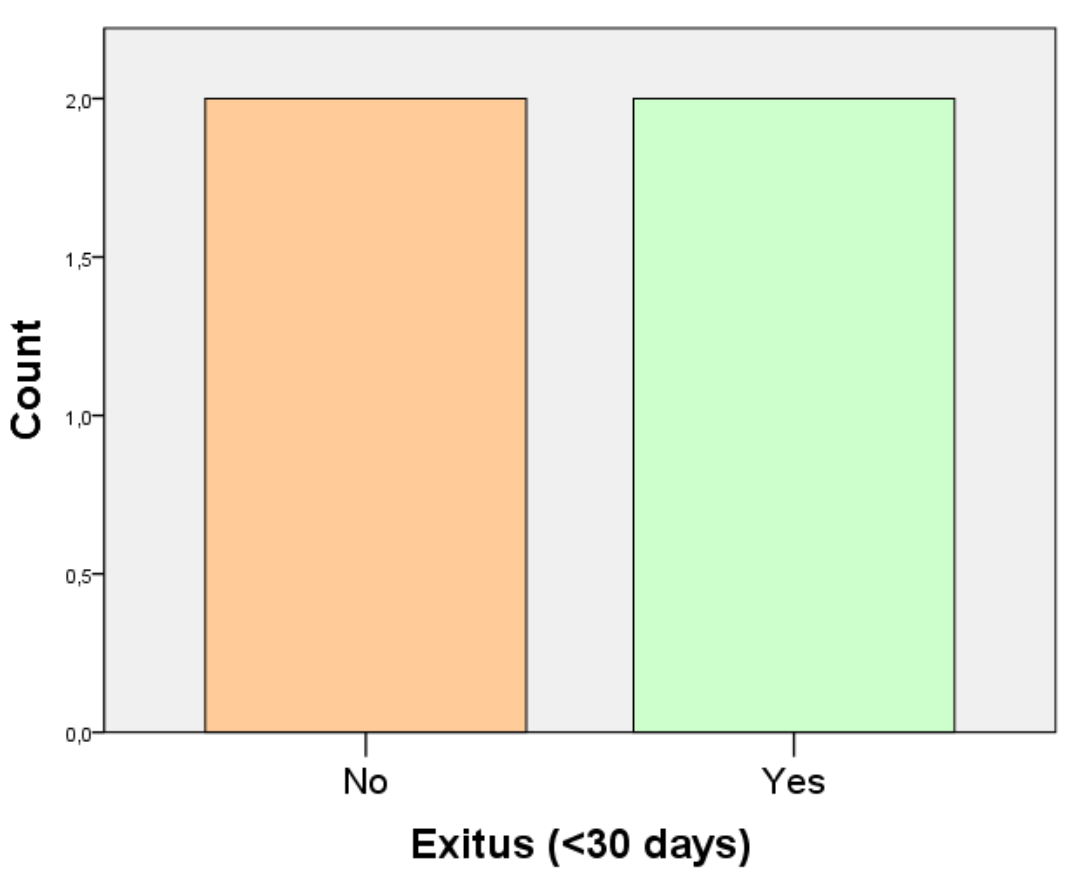

No statistical relationship could be found between the Lee

Index and the occurrence of episodes of heart failure or other cardiovascular events. 